\title{
Bedtime Stories In English: Field-Testing Comprehensible Input Materials For Natural Second-Language Acquisition In Japanese Pre-School Children
}

Robert Hamilton, Meiji University, Japan

\begin{abstract}
In this study, the prototype of a new type of bilingual picture book was field-tested with two sets of mother-son subject pairs. This picture book was designed as a possible tool for providing children with comprehensible input during their critical period for second language acquisition. Context is provided by visual cues and both Japanese and English (the target language) are used in the story, providing enough information for a child to be able to follow the story regardless of English proficiency level. The two mothers were asked to read the picture book to their children on a regular basis over the course of a month and to take notes on their children's reactions. The children's knowledge of target vocabulary was tested both before and after the trail. Results showed that while the children had no difficulty following the story or acquiring language by this method, the mothers were initially skeptical. This suggests that the greatest obstacle to using these materials for second language learning may lie in educating teachers and parents in how to use them and convincing them of the material's efficacy.
\end{abstract}

Keywords: Input Hypothesis; Children; Picture Book; Language Acquisition; Critical Period; Material Development

\section{INTRODUCTION}

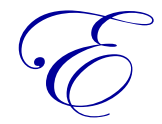

ver since Stephen Krashen proposed the Input Hypothesis (IH) of second language acquisition in the late 1970's, a wealth of educational courses and materials have been developed based on his research. Krashen's theory proposes that the most natural and effective way for an individual to acquire language is not by specifically studying and memorizing vocabulary or grammatical structures, but by being exposed to the target language at a difficulty level just slightly more advanced than the learner's current proficiency level (Krashen, 1981, 1985).

Extensive reading programs, for example, use graded readers that are divided by level of difficulty so that learners can select books with a level of difficulty that is well within their ability to comprehend without the use of a dictionary or other outside source. This allows the reader to continue for an extended period of time without having to leave the primary text, which not only exposes the language learner to more of the target language, but also contributes to both enjoyment of the material and the motivation to read more. New vocabulary and grammatical structures are acquired naturally when the reader encounters unfamiliar words or structures. Context provided by the rest of the story allows the reader to infer meaning, allowing a fluid reading experience uninterrupted by the need to use a dictionary or other reference text. The learner acquires the target language in a natural manner, in much the same way that a mother tongue is acquired (Hafiz \& Tudor, 1988; Beniko \& Krashen, 1997).

While graded readers are an effective form of comprehensible input for a certain group of language learners, they are impractical when it comes to very young children for obvious reasons. Children under five years of age are still in the early learning stage of literacy in their native tongue and do not have the skills required to read 
on their own. By the time a child gains the necessary reading and comprehension skills for an extensive reading program to be effective, they will have missed much of the accelerated language-learning window known as the critical period. While there is still some debate as to whether second language acquisition follows the same patterns and stages as first language acquisition, it is generally accepted that children will be able to master a second language more easily if they are exposed to that language in their early years, with estimates of that effective cut-off age for this critical period ranging from eight years of age to puberty (Fantini, 1985; Krashen et al., 1979; Snow et al., 1978). If we are to take advantage of this critical period for $\mathrm{L} 2$ learners, a program which adapts the continuous input of an extended reading program for children who have not yet developed literacy in their native language would be most useful.

A natural place to look for comprehensible input for this age group is in picture books. Reading picture books to children is a common practice and a proven method for teaching children to read and to develop communicative skills in their native language (Dulay \& Burt, 1974). Children who are read to by parents or teachers on a regular basis at this young age tend to develop a larger effective vocabulary, greater comprehension skills, and a greater ability to retell events or stories on their own. Combining picture book reading with questions and conversational interaction with a parent or teacher also greatly increases language development in L1 learners (Whitehurst et al., 2010). It is therefore reasonable to hypothesize that L2 input from picture books being read to a young child by a parent would help to improve second language acquisition during the critical period.

The materials being field-tested in this study have been designed to create L2 comprehensible input for children who are still learning to read in their native language. It was decided to create a picture book which would provide comprehensible input in the form of a bilingual story with a great degree of visual information so that children would be able to acquire the language naturally over the course of repeated readings. While there are already many bilingual picture books in existence, they generally fall into one of two categories: 1) books with translations in which the entire story appears in both languages or 2) books that are primarily in the child's native language, with a few words or phrases from the target language. The prototype book for this study, however, would be half in Japanese and half in English (the target language) creating a sort of information gap. Children already use contextual skills in order to acquire language and generate meaning in their native tongues. This book would ideally encourage them to use those same contextual clues and skills in order to understand the entire story, acquiring English vocabulary and phrases in the process.

\section{MATERIALS}

A child's picture storybook was created featuring two characters - a large creature named Gubbo and a small parasite-like being named Nebbin who lives in Gubbo's hair. In the story, the two characters gradually become aware of each other's existence and attempt to communicate with each other. Each creature speaks a different language (either English or Japanese), so they initially experience difficulties, but they manage to introduce themselves and to explain their pastimes. One of the characters is a painter, while the other is a musician. They explain these activities while demonstrating, so that children reading the books can be introduced to the vocabulary associated with these actions while having adequate visual input to compensate for their lack of L2 knowledge. By the end of the story, the two characters have learned about each other and become friends.

The book also has a unique structure. If read from one cover, the title of the book is Gubbo \& ネビン, and in this version of the story, Gubbo speaks English and all of the portions of the story involving Gubbo are in English. Likewise, Nebbin, whose name is written in Japanese in the title, speaks only Japanese and the story about him is written in Japanese. If the book is flipped over and read from the opposite cover, the book is called ガッボ\& Nebbin, in which Nebbin becomes the English speaker while Gubbo communicates and thinks in Japanese. There are no significant differences in the story, regardless of which character is speaking either Japanese or English. The sentences, however, are not written as exact translations. Instead, the essence and feeling of the passages are preserved through rather liberal translations. This is due to the fact that the linguistic structures of Japanese and English are significantly different as to make such a direct translation impossible, or at least extremely awkward and unnatural. Research has also shown that young children are capable of keeping the morphosyntax of two languages distinct as they learn (Yip, 2007), so differences in grammatical structure shouldn't cause any confusion to such young children. 
The story is written using a suitable vocabulary level for a young learner but is not strictly limited to suggested vocabulary for beginner's L2 learning. The working hypothesis upon creating the text was that motivation for repeated readings would be generated by interest in the characters and story, so creative story telling and artwork took precedence over vocabulary lists. As such, no corpus list or frequency study was used to determine what words to include. Instead, age-appropriate vocabulary was important, but story engagement was prioritized. Because 50\% of the story is in a foreign language regardless of which way the story is read, the pictures and context have been designed to provide enough information and context for a child to be able to understand the story and fill in any information gaps on his or her own (Figure 1).

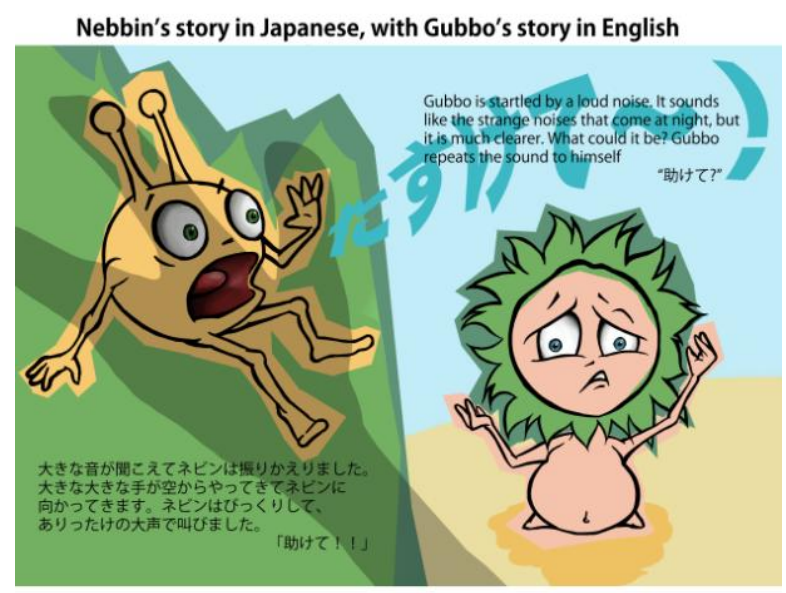

Nebbin's story in English, with Gubbo's story in Japanese

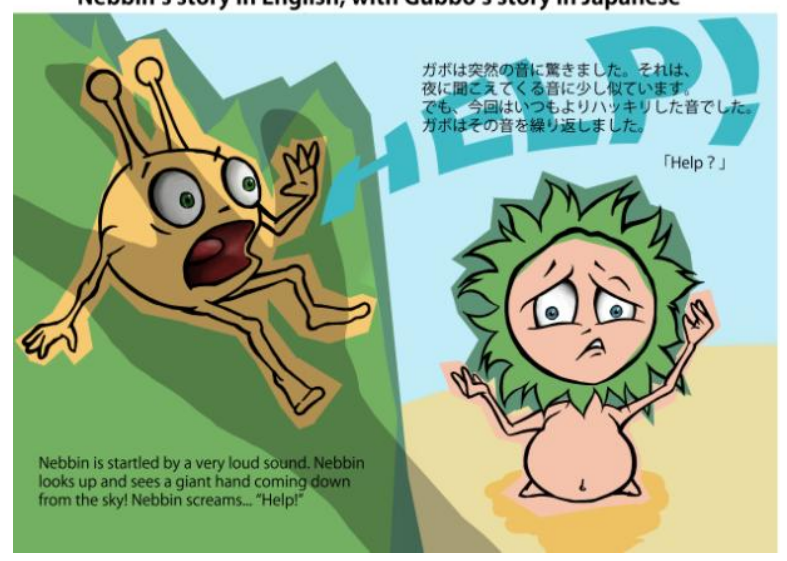

\section{METHODOLOGY}

A prototype of the book was given to two Japanese mothers to read to their children. They were instructed to read the book to them at least three times a week for the duration of one month, or for as long as the child remained interested. Each reading was to alternate between the version in which Gubbo speaks English and the version in which Gubbo speaks Japanese. While reading through the story, they were asked to read the Japanese portions in Japanese and the English portions in English without skipping over any of the dialogue or explanation. If a child specifically asked the meaning of an English word or sentence, the mother could either explain the meaning in Japanese, or ask the child what he thought it meant. Other than answering questions from the children, no translation was to occur and the meanings of foreign passages were to be communicated to the children through context, visual images, and repetition.

Subject pair A (Yoko and Sho): Yoko is a freelance translator who studied in England when she was younger. She has native-level English ability but speaks only Japanese with her family. Sho is a 4-year old boy. He 
is very interested in picture books and Yoko reads to him every night before bed. He is not yet able to read on his own.

Subject pair B (Rie and Ken): Rie is a stay-at-home mother. She has intermediate English ability but has never spent more than a few of months at a time in an English-speaking country. Ken is a 4-year old boy who enjoys listening to Rie read picture books but was not previously on a regular schedule of bedtime stories.

During the course of the month, each mother was asked to write her impressions of the process in a journal. They were also asked to focus on these key questions and guidelines:

1) Write down any English words or phrases that your child specifically asks the meanings of.

2) Write down any English words or phrases from the book that your child spontaneously repeats or uses during the course of the month.

3) Occasionally ask your child to explain portions of the book in order to determine whether or not he understands the storyline.

4) Take note of any waning interest in the story after repeated readings.

5) Take note of any issues that you felt prevented your child from either enjoying or learning from this material.

\section{RESULTS}

One of the main concerns heading into this trial was that perhaps children would not tolerate listening to large portions of a story in a foreign language or that they might not be able to understand the relationship between the two characters without some overarching explanation in their native language. Although both mothers also stated that they thought their children might grow restless during the English passages, the children themselves showed little or no resistance to the concept. Both children were able to understand the story clearly, regardless of which character was speaking Japanese or English. Furthermore, neither child asked for an explanation as to why each character spoke a different language.

Both mothers were more concerned with the English content than their children. Rie, especially, was initially slightly uncomfortable with reading half of the story in English. As an intermediate level speaker, Rie still has a marked Japanese accent and questioned whether her imperfect pronunciation or intonation might have a negative effect on her son. She grew more comfortable with the concept after repeated readings, but still suggested that this sort of book should come with a CD of the English narration so that parents could listen to it and practice imitating the voice on the $\mathrm{CD}$ before reading to their children for the first time.

As storybooks are often read to children multiple times, it comes as little surprise that neither boy grew tired of hearing the same story multiple times, and both boys occasionally asked for the mothers to read Gubbo and Nebbin to them. Three times a week, however, appears to have been too frequent. Neither boy would normally have been read the same book three times a week over an extended period of time. This suggests that further field tests should involve a lower frequency of recommended readings for each individual title. This will more realistically reproduce an average child's reading routine.

Pre- and post-trial testing revealed that both boys acquired the following words and phrases during the one month trial: Friend, ouch, help, hello, song, nice to meet you, good night. Both mothers also reported that terms such as "hello" and "good night" were spontaneously used by their children at appropriate times. Of the two boys, Sho, whose mother is a native-level speaker of English, was able to acquire more English vocabulary and phrases than Ken. This could possibly be explained by previous exposure to English. Although Yoko and Sho only speak Japanese at home, he would likely have heard his mother speaking English to colleagues and friends. Even though the two boys seemed to have a similar level of English in pre-trial testing and interviews, Sho likely had some passive knowledge that had not yet been activated.

Interest in learning English was markedly improved in both trial pairs. During the course of the one-month trial, Sho told his mother that he would like to become a fluent speaker of English, a sentiment that he had never 
expressed before. Ken told his mother that he was enjoying Gubbo and Nebbin and asked if she could get some other English books to read to him as well. This increased interest in learning a foreign language indicates that although both boys were put on a schedule for the purposes of learning a foreign language, they both felt that it was an enjoyable experience. Follow-up interviews confirmed that this increased interest in the English language persisted after the conclusion of the month-long trial and Gubbo and Nebbin remained in the night-time reading rotation.

\section{FURTHER RESEARCH AND DEVELOPMENT}

Although the prototype book was successful in both helping the subject children to acquire the target language and to increase their motivation for learning, there are still some hurdles to overcome before this type of book might be successfully used in homes across Japan. The greatest barrier to widespread use is apparent in the reaction that Rie initially had to reading the English-language portions of the book to Ken. Most parents and many teachers in Japan will not have the English background or the confidence that would cause them to choose such a book for reading to their child. Neither of the children had trouble understanding the concept and Rie also become comfortable after the first couple of readings. However, she admitted that she never would have purchased a book like that for her child. This is a significant point because children don't buy books. Parents and educators buy books for children. Regardless of how well a book is able to provide comprehensible input for a child, if parents or teachers are not willing to try, the children will never be exposed to it.

Before the next field study, some supplemental material is needed in order to explain to parents or educators how the book may be used and to reassure them of the ease and effectiveness with which it can be used. Care will be needed in order to keep such supplemental material brief and clear. If it appears to be a teacher's manual of sorts, then it will be equally likely to discourage parents. Since a home reading environment with repeated readings is the most effective environment for this type of material, it is imperative that the material be approachable for average parents.

\section{AUTHOR INFORMATION}

Robert Hamilton is an associate professor in the School of Global Japanese Studies at Meiji University in Tokyo, Japan. Having a background in both visual arts and second-language education, Prof. Hamilton has recently been exploring ways to use visual context to help facilitate EFL acquisition in early childhood language learners. E-mail: robert@hamihami.net

\section{REFERENCES}

1. Beniko, M., \& Krashen, S. D. (1997). Extensive reading in English as a foreign language. System, 25(1), 91-102.

2. Doughty, C., \& Pica, T. (1986). "Information gap" tasks: Do they facilitate second language acquisition? TESOL Quarterly, 20(2), 305-325.

3. Dulay, H. C., \& Burt, M. K. (1974). Errors and strategies in child second language development. TESOL Quarterly, 8(2), 129-136.

4. Fantini, A. E. (1985). Language acquisition of a bilingual child: A sociolinguistic perspective (to age ten). Clevedon: Multilingual Matters.

5. Hafiz, F. M., \& Tudor, I. (1988). Extensive reading and the development of language skills. ELT Journal, 43(1), 4-13.

6. Krashen, S. D. (1981). Second language acquisition and second language learning. Oxford: Pergamon.

7. Krashen, S. D., Long, M. A., \& Scarcella, R. C. (1979). Age, rate and eventual attainment in second language acquisition. TESOL Quarterly, 13(4), 573-582.

8. Krashen, S. D. (1985). The input hypothesis: Issues and implications, New York: Longman

9. Long, M. H., \& Porter, P. A. (1985). Group work, interlanguage talk, and second language acquisition. TESOL Quarterly, 19(2), 207-228.

10. Snow, C. E., Hoefnagel-Höhle, M., \& Hoefnagel-Höhle, M. (1978). The critical period for language acquisition: Evidence from second language learning. Child development, 49(4), 1114-1128. 
11. Whitehurst, G. J., Falco, F. L., Lonigan, C. J., Fischel, J. E., DeBaryshe, B. D., Valdez-Menchaca, M. C., \& Caulfield, M. (1988). Accelerating language development through picture book reading. Developmental Psychology, 24(4), 552.

12. Whitehurst, G. J., \& Valdez-Menchacha, M. C. (1988). What is the role of reinforcement in early language acquisition. Child Development, 59(2), 430-440.

13. Yip, V., \& Matthews, S. (2007). The bilingual child: early development and language contact. Cambridge, UK: Cambridge University Press. 